\title{
A Case of the 7p22.2 Microduplication: Refinement of the Critical Chromosome Region for 7p22 Duplication Syndrome
}

\author{
Devin M. Cox ${ }^{1,2}$ Merlin G. Butler ${ }^{1,2}$ \\ ${ }^{1}$ Department of Psychiatry, University of Kansas Medical Center, \\ Kansas City, Kansas, United States \\ 2 Department of Behavioral Sciences and Pediatrics, University of \\ Kansas Medical Center, Kansas City, Kansas, United States
}

\author{
Address for correspondence Devin M. Cox, MS, Department of \\ Psychiatry, Kansas University Medical Center, 3901 Rainbow \\ Boulevard, MS 4015, Kansas City, KS 66160, United States \\ (e-mail: dcox2@kumc.edu).
}

J Pediatr Genet 2015;4:34-37.
Abstract
Keywords
- 7p22.2 duplication
- microarray analysis
- dysmorphic features
- mild intellectual disability

We report a 14-year-old Hispanic male with a microduplication of the chromosome 7p22.2 band detected through microarray analysis. He had a history of developmental delay and mild intellectual disability, asthma, myopia, proportionate short stature, dysmorphic features, and Achilles tendon release. This appears to be the first report of a patient with a microduplication of only the chromosome 7p22.2 band and is now the smallest reported duplication to date to include features in common with the chromosome 7p22 duplication syndrome.

\section{Introduction}

Partial chromosome $7 \mathrm{p}$ duplication has been reported in at least 60 individuals and generally associated with unbalanced chromosome translocations. ${ }^{1-3}$ However, chromosome $7 \mathrm{p}$ duplication can arise de novo, possibly because of nonallelic homologous recombination. ${ }^{1}$ The short arm of chromosome $7 \mathrm{p}$ includes 17 bands and sub-bands at high-resolution 850band level. The chromosome 7p22 band consists of three subbands and is often implicated in the $7 \mathrm{p}$ duplication syndrome. Papadopoulou et $\mathrm{al}^{2}$ provided a review of the $7 \mathrm{p}$ duplication syndrome and reported that the most common phenotypic findings were intellectual disability, hypotonia, abnormal palmar creases, skeletal abnormalities (broad halluces/ thumbs/digits, foot and thorax malformations, joint contractures, or dislocations), cardiovascular abnormalities, and craniofacial dysmorphism (large anterior fontanel, ocular hypertelorism, low-set ears, high-arched, and/or cleft palate). Vulto-van Silfhout et $\mathrm{al}^{4}$ reported the smallest known duplication in the chromosome 7p22.3 sub-band (380 kb in size) in a patient presenting with only an autism spectrum disorder (Asperger syndrome) and a broad nasal bridge. Later, Preiksaitiene et $\mathrm{al}^{3}$ reported the smallest $7 \mathrm{p}$ duplication (1 Mb duplication) at $7 \mathrm{p} 22.1$ with features consistent with the recognized phenotype seen in this duplication syndrome.

We report a patient with a $629 \mathrm{~kb}$ duplication at $7 \mathrm{p} 22.2$ (position 2,878,677-3,507,572, National Center for Biotechnology Information [NCBI] build 36), the sub-band located between $7 \mathrm{p} 22.1$ and $7 \mathrm{p} 22.3$. Our patient presented with features of the $7 \mathrm{p}$ duplication syndrome, yet harbors the smallest reported chromosomal duplication to date. Importantly, our patient shares phenotypic features in common with patients described with the $7 \mathrm{p}$ duplication of larger size. This is also the first patient reported with a duplication at chromosome 7p22.2 sub-band; allowing for better delineation of the clinical presentation of this chromosomal duplication syndrome and further determination of the chromosomal critical region.

\section{Case Report}

Our patient is a 14-year-old Hispanic male who presented for genetic evaluation for developmental delay and dysmorphic features. The patient was the product of an unremarkable fullterm pregnancy weighing $3.010 \mathrm{~g}$ (17th centile). Developmental milestones were delayed; he sat up at 12 months, received

December 11, 2014

accepted after revision

March 1, 2015
Copyright $\odot 2015$ by Georg Thieme

Verlag KG, Stuttgart · New York
DOI http://dx.doi.org/ 10.1055/s-0035-1554980. ISSN 2146-4596. 
walked at 2 years, spoke his first word at 2 years, and used two-word sentences at 3 years of age. Our patient had polyethylene ear tubes placed on three separate occasions between the age of 2.5 and 5 years. He began speaking after the first set of ear tubes. At the age of 8 years, he was administered the Wechsler Intelligence Scale for Children with the following derived scores: verbal intelligence quotient 57, performance intelligence quotient 58, full-scale intelligence quotient 53 , verbal comprehension 61 , and perceptual organization 56. He has had an individualized education plan in place since entrance in the school system requiring special education services. He receives 20 minutes of speech therapy every month. He is currently in the 9th grade. Health issues include asthma, which is well-controlled, and corrective glasses for myopia. At the age of 11 years, he had bilateral Achilles tendon release surgery to correct a toewalking gait, and later at the age of 12 years, additional corrective surgery of the left foot was undertaken because of the malposition interfering with walking.

Our patient had an extensive genetic work up in the past including a karyotype to explore the possibility of Down syndrome performed at the age of 12 years, which showed a normal male karyotype. He had fragile-X DNA testing performed at the age of 13 years, which was also normal. He had two separate microarrays, one at the age of 10 years and the other at the age of 13 years. At the age of 10 years, a single nucleotide polymorphism (SNP) microarray analysis was performed using the Affymetrix 6.0 SNP array with 1.8 million probes consisting of 900,000 SNP probes and 900,000 copy number probes with a median spacing of $0.7 \mathrm{~kb}$ (LabCorp, Research Triangle Park, North Carolina, United States). Data were analyzed using the Affymetrix Genotyping Console Browser v. 3.01 (Affymetrix, Santa Clara, California, United States) and genomic imbalances reported using the University of California Santa Cruz (UCSC) Human Genome Build 18 (NCBI build 36; 2006). This array showed a $629 \mathrm{~kb}$ duplication involving the chromosome 7p22.2 band (hg18 coordinates chr7:2878677-3507572). Maternal studies were performed using a custom-designed familial follow-up protocol with region-specific fluorescence in situ hybridization bacterial artificial chromosome probe(s) (RP11-659F18 $\times 2$ ) (LabCorp, Research Triangle Park) showing a normal copy number and hybridization signals in all nuclei. The father was unavailable for testing. At the age of 13 years, an Affymetrix CytoScan (Affymetrix, Santa Clara, California, United States) HD microarray was performed containing 2.6 million probes with at least one probe per $3 \mathrm{~kb}$. Genomic imbalances were reported using the UCSC Human Genome Build 1A (NCBI build $37 ; 2009$ ) and the array showed a $634 \mathrm{~kb}$ duplication involving the same chromosome 7p22.2 band (hg19 coordinates chr7:2907375-3541046) as found earlier and included two known genes (caspase recruitment domain family, member 11 [CARD11] and sidekick cell adhesion molecule 1 [SDK1]).

During the physical examination at the age of 14 years, he was a pleasant Hispanic male with dysmorphic features including prominent appearing supraorbital ridges, mild synophrys, slightly upslanting palpebral fissures, relatively small and irregularly-shaped pupils, malar hypoplasia, lowset protruding ears with prominent lobes, posterior creases and pit-like depressions located bilaterally, hypoplastic alae nasi with depressed nasal tip and a narrow appearing nose, a high-arched palate, alopecia areata $(2 \times 3 \mathrm{~cm})$ located in the left occipital region, a café au lait spot measuring $0.5 \mathrm{~cm}$ in size in the center of the abdomen, malalignment of feet, and proportionate short stature. His reflexes were normal of both the lower and upper extremities along with normal coordination. No edema, joint laxity or tenderness, leg length asymmetry, other cutaneous lesions, abdominal masses/tenderness, or respiratory distress, were noted. His height was $146.8 \mathrm{~cm}$ ( $<3$ rd centile), weight $63.86 \mathrm{~kg}$ (80th centile), head circumference $54 \mathrm{~cm}$ (50th centile), inner canthal distance $2.9 \mathrm{~cm}$ (30th centile), outer canthal distance $7.8 \mathrm{~cm}$ (3rd centile), interpupillary distance $5.2 \mathrm{~cm}$ (15th centile), palpebral fissure $2.5 \mathrm{~cm}$ (11th centile), ear length $5.7 \mathrm{~cm}$ (35th centile), total hand length $16.3 \mathrm{~cm}$ (14th centile), and middle finger length $6.3 \mathrm{~cm}$ (<3rd centile) ( $<$ Fig. 1). The family history was remarkable for four paternal half-siblings who were reported to have learning disabilities. There are two paternal half-sisters and two paternal half-brothers. All were at the age of 6 years or younger. One paternal half-brother reportedly wears hearing aids and has a similar physical appearance to our patient. No further family history or information about the father was available, although our proband apparently had several physical features in common with his father.

\section{Discussion}

Duplications of chromosome 7p22 are known to cause a spectrum of phenotypic features as seen in our 14-year-old male patient with a full-scale intelligence quotient of 53 , developmental delays, and dysmorphic features. To our knowledge, the patient's duplication at 7p22.2 is the smallest found to date while still containing the phenotypic features seen in the $7 p$ duplication syndrome. We examined five cases reported in the literature and web-based resources of genomic variation data (e.g., DECIPHER). Three cases (cases C, D, and $\mathrm{E}$ ) had overlapping genomic regions in common with our patient (case F; see - Fig. 2) ${ }^{5}$ The 7p22 duplications in the five previous reported cases ranged from 390 to $980 \mathrm{~kb}$. Three of the cases found in the DECIPHER database ${ }^{5}$ had genomic coordinates located at 3.14 to $3.30 \mathrm{Mb}$ from the p terminus region, approximately $160 \mathrm{~kb}$ in length, which overlaps with our patient's microduplication. This overlapped region includes the CARD11, SDK1, and guanine nucleotide-binding protein (G protein) $\propto 12$ (GNA12) genes.

Our patient's deletion included two genes, caspase recruitment domain family, member 11 (CARD11) and sidekick cell adhesion molecule 1 (SDK1). The CARD11 gene is associated with autosomal dominant persistent polyclonal B cell lymphocytosis (OMIM \# 606445) and autosomal recessive immunodeficiency type 11 (OMIM \# 615206). The SDK1 gene may be associated with determinants of lamina-specific synaptic connectivity specifically playing a role in neurodevelopment and function. ${ }^{6}$ 

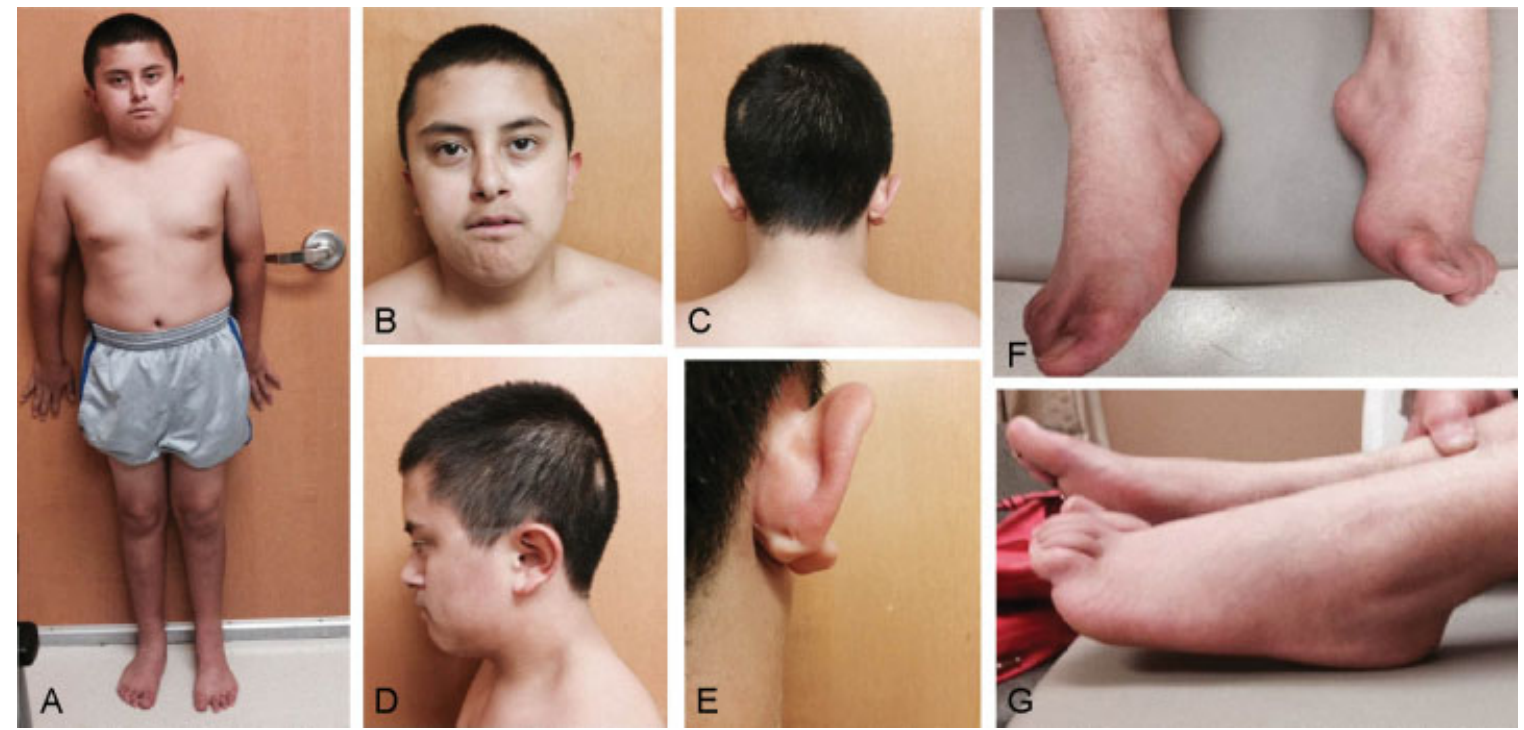

Fig. 1 (A-G) Standing and facial, frontal, and profile views with images of back of head and ears and feet from our patient having a $7 \mathrm{p} 22.2$ microduplication found by microarray analysis.

\section{Chromosome 7}

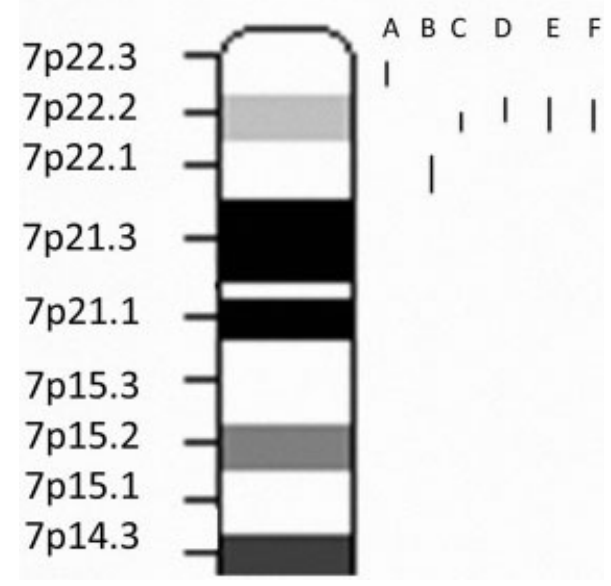

Fig. 2 Location of interstitial chromosome 7p22 duplication for our patient and others reported in the literature and genomic databases. Deletions of previously reported subjects are indicated as; (A) Interstitial gain in band p22.3 of chromosome 7 estimated at a minimal size of $380 \mathrm{~kb}$ to a maximal size of $450 \mathrm{~kb}$ in a patient with Asperger syndrome, ${ }^{4}$ (B) $980 \mathrm{~kb}$ duplication of 7p22.1 region in a patient with features consistent with 7p22 duplication syndrome (position $5,337,072-6,316,915$, NCBI build 36), ${ }^{3}$ (C) DECIPHER case 292740 , $389 \mathrm{~kb}$ gain at 7p22.2 (position 3,142,074-3,531,219, NCBI build 36) involving only the SDK1 gene in a patient with cognitive impairment, ${ }^{5}$ (D) DECIPHER case $274816,450 \mathrm{~kb}$ gain at 7p22.2 (position $2,845,372-3,298,538$, NCBI build 36) involving the CARD11 and GNA12 genes in a patient with generalized tonic seizures, ${ }^{5}$ (E) DEClPHER case 282143, $763 \mathrm{~kb}$ gain at 7p22.2 (position 2,817,874$3,580,692$, NCBI build 36) involving the SDK1, CARD11, and GNA12 genes in a patient with a second copy number variant on chromosome 6 and having a heart abnormality, cerebellar vermis hypoplasia, and renal hypoplasia/aplasia, ${ }^{5}$ and (F) our patient with a 629 kb duplication at 7p22.2 (position 2,878,677-3,507,572, NCBI build 36). The smallest region of overlap among the four subjects with the 7p22.2

duplication occurred between the genomic coordinates 3.14 and 3.30 $\mathrm{Mb}$ from the $p$ terminus.
Interstitial duplications of the $7 \mathrm{p} 22.1$ band have been reported previously ${ }^{1,3}$ with characteristic features of the $7 p$ duplication syndrome including macrocephaly, open anterior fontanel, frontal bossing with a flat, broad nasal bridge, ocular hypertelorism, anteverted nares, microretrognathia, high narrow palate, microstomia, low-set posteriorly rotated ears with preauricular pit, speech delay, and skeletal anomalies. Our patient's cytogenetic duplication does not overlap with previously identified microduplications of 7p22.1 as his duplication is located more telomeric at the 7p22.2 sub-band, although he had several features in common with the partial $7 \mathrm{p}$ duplication syndrome including prominent appearing supraorbital ridges, slightly upslanting palpebral fissures, malar hypoplasia, low-set protruding ears with posterior creases and depressions with prominent lobes, hypoplastic alae nasi, depressed nasal tip with a narrow appearing nose, a high-arched palate, speech delay, and intellectual disability.

In conclusion, this clinical case is of interest as the first report of a microduplication of the 7p22.2 sub-band with dysmorphic features similar to those reported in the partial $7 p$ duplication syndrome; indicating that the $7 p 22.2$ subband may play a role in this phenotype. Our patient's chromosome duplication does not overlap with previously reported 7p22.1 microduplications. Further research is needed to determine the role of the $7 \mathrm{p} 22.2$ microduplication in causing the $7 p$ duplication syndrome. Reporting further cases with microduplications of the $7 p$ region are encouraged to better characterize the dosage-sensitive candidate gene(s) resulting in features seen in the partial $7 p$ duplication syndrome. These microduplications would only be detected using high-resolution microarray analyses. The smallest region of overlap in the 7p22.2 band was positioned at genomic coordinates located at 3.14 to $3.30 \mathrm{Mb}$ from the chromosome $7 \mathrm{p}$ terminus in our patient (case F) and for cases $\mathrm{C}, \mathrm{D}$, and $\mathrm{E}$ from the DECIPHER database as illustrated in - Fig. $2^{5}$ 


\section{Acknowledgment}

We acknowledge support from the HD02528 grant from the National Institute of Child Health and Human Development.

\section{References}

1 Chui JV, Weisfeld-Adams JD, Tepperberg J, Mehta L. Clinical and molecular characterization of chromosome 7p22.1 microduplication detected by array CGH. Am J Med Genet A 2011;155A(10):2508-2511

2 Papadopoulou E, Sifakis S, Sarri C, et al. A report of pure 7p duplication syndrome and review of the literature. Am J Med Genet A 2006;140(24):2802-2806
3 Preiksaitiene E, Kasnauskiene J, Ciuladaite Z, Tumiene B, Patsalis PC, Kučinskas V. Clinical and molecular characterization of a second case of 7p22.1 microduplication. Am J Med Genet A 2012;158A(5):1200-1203

4 Vulto-van Silfhout AT, de Brouwer AF, de Leeuw N, Obihara CC, Brunner HG, de Vries BB. A 380-kb duplication in 7p22.3 encompassing the LFNG gene in a boy with Asperger syndrome. Mol Syndromol 2012;2(6):245-250

5 Firth HV, Richards SM, Bevan AP, et al. DECIPHER: database of chromosomal imbalance and phenotype in humans using Ensembl resources. Am J Hum Genet 2009;84(4): 524-533

6 Yamagata M, Weiner JA, Sanes JR. Sidekicks: synaptic adhesion molecules that promote lamina-specific connectivity in the retina. Cell 2002;110(5):649-660 